\title{
Exploring the interplay between human and machine annotated multimodal learning analytics in hands-on STEM Activities
}

\author{
Daniel Spikol \\ Malmö University \\ Malmö, Sweden \\ daniel.spikol@mah.se
}

\author{
Katerina Avramides \\ UCL Institute of Education \\ London, UK \\ K.Avramides@ioe.ac.uk
}

\author{
Mutlu Cukurova \\ UCL Institute of Education \\ London, UK \\ m.cukurova@ioe.ac.uk
}

\begin{abstract}
This poster explores how to develop a working framework for STEM education that uses both human annotated and machine data across a purpose-built learning environment. Our dual approach is to develop a robust framework for analysis and investigate how to design a learning analytics system to support hands-on engineering design tasks. Data from the first user tests are presented along with the framework for discussion.
\end{abstract}

\section{Keywords}

Mobile, Learning Analytics, CSCL

\section{INTRODUCTION}

There is concern amongst policy makers and employers that students are not graduating with the required skills in STEM subjects (Science, Technology, Engineering, and Mathematics). It is argued that learners must go beyond the acquisition of discipline-specific facts and skills, to develop an integrated understanding of STEM disciplines within an authentic context of collaborative problem-solving. This integrated approach to STEM teaching is at the heart of instructional practices that centre on collaborative, hands-on, engineering design problems [4. The use of hands-on engineering design problems, in classroom teaching, is facilitated by physical computing kits, such as the Arduind 1 , and other platforms. These kits provide building blocks that make technology development more accessible to novices, thus allowing them to work on more complex problems. A finegrained analysis of the collaborative problem-solving process, using learning analytics tools, can provide insight into learning to support both teachers and learners. However, it is hard to track and interpret learner activity in engineering design problems, due to the hands-on and open-ended nature of such tasks [3]. This poster presents work that be-

\footnotetext{
${ }^{1}$ www.arduino.cc
}

Permission to make digital or hard copies of all or part of this work for personal or classroom use is granted without fee provided that copies are not made or distributed for profit or commercial advantage and that copies bear this notice and the full citation on the first page. Copyrights for components of this work owned by others than ACM must be honored. Abstracting with credit is permitted. To copy otherwise, or republish, to post on servers or to redistribute to lists, requires prior specific permission and/or a fee. Request permissions from permissions@ acm.org. gins to address this challenge. We discuss the development of a coding process for exploring hands-on STEM activities, using physical computing kits, that uses both handannotated and machine data across a purpose-built learning environment. The research aim is to investigate how we can support a combination of realtime hand-annotated data collected with machine collected data to help understand the complexities of collaborative problem solving.

\section{BACKGROUND}

This work is part of the PELARS project ${ }^{2}$ which explores teaching and learning of STEM using physical computing kits and open-ended engineering design tasks. The aim of PELARS is to develop learning analytics tools that support teachers and students. There is limited research on learning analytics within this context, due to the difficulty of tracking and interpreting student activity [3]. Researchers, in this area, have primarily focused on using learning analytics tools to gain a more fine-grained understanding of patterns of problem-solving between novices and experts, generally with a strong focus on individual rather than collaborative learning [1] 3 . However, collaborative learning has a central role in formal education. There is a wealth of research that suggests collaboration, compared with individual work, can foster better problem-solving and greater learning outcomes [2]. Collaboration supports learners to articulate their thinking and listen to others, as well as resolve conflicts and build on new ideas. Therefore, opportunities for new research that combine multimodal learning analytics with hands-on collaborative learning are present for further investigation.

\section{TOOLS AND SETTINGS}

The tools described in the poster consist of a purpose-built learning environment with multiple sensors to collect data during practice-based activities, with added web and mobile tools for learners to document their learning activities. The learning environment is a designed workshop that includes a specially designed table connected to a freestanding wall with a built-in display. This special work area accommodates a small group up to 4 students. The workstation includes a computer vision system with facial and object tracking (fiducial marks), log files from the programming of physical computing kits, as well as tracking of the different physical components that are being used by the students.

\footnotetext{
${ }^{2}$ www.pelars-project.eu
} 
Table 1: Breakdown of data collection

\begin{tabular}{lcl}
\hline Data Collection & Types of Data & Coding \\
\hline Computer Vision & Arm Tracking, Audio Levels, Motion, Objets & Machine \\
\hline Visual Electronics Platform & Components connected and coding actions & Machine \\
\hline Sentiment Buttons & Frequency Affective states & Machine \\
\hline Mobile System & Research coding, learner documentation & Machine and Human \\
\hline
\end{tabular}

Audio levels are captured (in the current release), and we have created two large buttons that students can push to signify sentiment (thunder cloud and sun). These buttons trigger the system to capture a screenshot of the programming activity and photo of the action on the table. Students need to plan, document, and reflect on their solution by entering brief text descriptions and capture photographs and video through the mobile system. More interestingly (for this poster) the mobile system provides a tool for research observations to be marked (in a temporal sense) "on the fly", providing a bridge between the data that the system collects. Table 1 illustrates the different type of data collected, what sensors, and the split between machine and human data collection and coding. The annotation data created by the researchers and the learners serves as a coarse temporal breakdown of the activities. These web-based mobile tools (cross platform) also provide a key tool for researchers to provide course realtime encoding based on an analysis framework for collaborative work. It is our intention to explore how this rougher coding done by researchers and learners could supply more automatic segmentation between the different design activities, thus structuring the machine collected data.

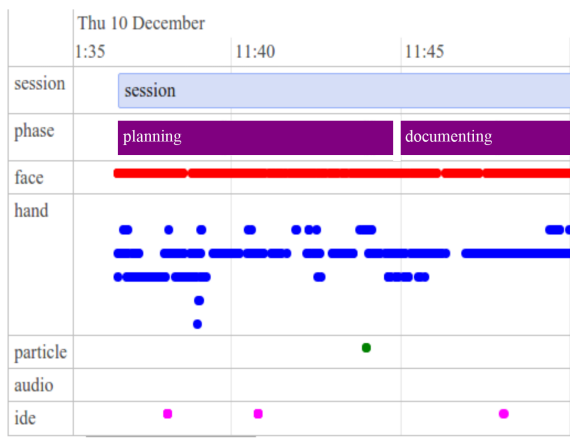

Figure 1: Detail of initial visualisation based realtime coding

\section{DATA COLLECTION}

As of writing this poster, the project has conducted its first full test of the system with two groups of three students with mixed backgrounds. The user trial procedure was to set up the test and introduce the students to the system. Each of the students wore fiducial tags for the vision system on their dominant arm and were shown how to use the mobile reporting system. Then the students were guided with an hands-on introduction to the visual programming platform (IDE) that included working with sensors and actuator blocks and programming them. The task of prototyping an interactive toy in 30 minutes was introduced and the learning analytics system started. The research observer using the mobile device began the coding of the activity with marking events (design stages of project scoping, project realisation, and reflection) while the students used the tool to capture planning, documenting, and reflecting. Figure 1 visualises the breakdown of planning, building, and reflecting across the different data that generated by the combination of research observations and the students input. Our initial work with the data has been to generate a rough visualisation as a first attempt to reflect on the data. We present the sum of all learners hand movements and the gaze at the display. We also include the number of times students interacted with the electronics and the IDE. We generated a simple timeline diagram divided into 3 phases illustrating the duration of these high-frequency events in the different phases.

\section{DISCUSSION}

The ability to use both the researcher codes of the different design stages [1] 3 and the students own classification of their activities suggests a rapid way to break down the data collected into appropriate parts for analysis and visualisation. Of course, questions and work remain to test further this process of using multimodal data and encoded annotations in comparison to more traditional hand coding of the video analysis in the project.

\section{ACKNOWLEDGMENTS}

The PELARS Project has received funding from the European Commission's Seventh Framework Programme for research, technological development and demonstration under grant agreement no. 619738 .

\section{ADDITIONAL AUTHORS}

Bahtijar Vogel (Malmö University bahtijar.vogel@mah.se), Rose Luckin (UCL IOE, R.Luckin@ioe.ac.uk), Emanuele Ruffaldi (Scuola Superiore Sant'Anna, e.ruffaldi@sssup.it) and Mavrikis, Manolis (UCL IOE, jm.mavrikis@ucl.ac.uk).

\section{References}

[1] C. J. Atman, R. S. Adams, M. E. Cardella, J. Turns, S. Mosborg, and J. Saleem. Engineering Design Processes: A Comparison of Students and Expert Practitioners. Journal of Engineering Education, 96(4):359-379, Jan. 2013.

[2] B. Barron. Achieving coordination in collaborative problemsolving groups. The Journal of the Learning Sciences, 9(4):403-436, 2000.

[3] M. Worsley and P. Blikstein. Analyzing Engineering Design through the Lens of Computation. Journal of Learning Analytics, 1(2):151-186, Aug. 2014.

[4] D. L. Zeidler. Dancing with maggots and saints: Visions for subject matter knowledge, pedagogical knowledge, and pedagogical content knowledge in science teacher education reform. Journal of Science Teacher Education, 13(1):27-42, 2002. 